\title{
Developing and Testing an Inter-disciplinary Course of Sustainable Technol- ogy Innovation for Urban Design
}

\section{Prof. Xiaojing Yuan, University of Houston, College of Technology (MERGED MEMBERSHIP WITH COE)}

Dr. Xiaojing Yuan is Associate Professor in the Computer Engineering Technology program of Engineering Technology Department. She is the founder and director of the Intelligent Sensor Grid and Informatics (ISGRIN) research lab and actively involving undergraduate researcher in her research on networked smart data acquisition systems, wireless sensor networks, and data analytics of the data collected. Her research interest also includes quality-of-service enhanced networking protocols, pattern recognition, data mining, and their applications in cyber security.

\section{Dr. Bruce Alan Race FAIA, FAICP, University of Houston}

Bruce Race, FAIA, FAICP, PhD joined the Gerald D. Hines School of Architecture as Director of University of Houston's newly created Center for Sustainability and Resilience (CeSAR). Prior to joining UH, Dr. Race was an Associate Professor of Practice and a full-time faculty for Ball State University's Master of Urban Design program in Indianapolis. His design talent, practice experience, and research interests intersect in his classroom studios where he emphasizes community engagement and design innovation grounded by real world experience.

Dr. Race is the principal and founder of RACESTUDIO and is responsible for all aspects of project planning, design and delivery. Since founding RACESTUDIO in Berkeley, CA in 1994, his projects have received 32 design and planning awards including national awards from the American Institute of Architects, American Planning Association, Environmental Protection Agency and Society of College and University Planning. The Long Range Development Plan for UC Merced received a national 2012 AIA COTE Top Ten Green Projects Award, and the Owings Award for Environmental Excellence, from the California Architectural Foundation in 2013. 


\title{
Develop and Test an Interdisciplinary Course of Sustainable Urban Design and Technology Innovation
}

\author{
Xiaojing Yuan, Bruce Race \\ University of Houston, xyuan@uh.edu
}

\begin{abstract}
Architecture and engineering technology students are entering professions that demand innovation and interdisciplinary leadership. Community policies, building codes, professional organizations' ethics, and emerging business models are shifting. Urban development policy and building practices are emphasizing climate and people friendly cities. Cities are pursuing policies for new and existing development to meet aggressive greenhouse gas (GHG) energy, waste, and water targets. Achieving contemporary environmental policies requires the collaboration of architects and engineers. Students should be prepared to become active contributors and leaders in the design, development, and management of high-performance districts and cities. In this paper, the authors are sharing the process of creating and co-teaching an interdisciplinary ecodistrict course. The paper includes the course's learning objectives, rubrics, assignments, case studies, class projects, and learning outcomes. The paper also details the learning and practice environment developed to instill the confidence to work in interdisciplinary teams. Case studies and the final project allowed students the opportunity to apply design thinking and problem solving in an interdisciplinary fashion. In addition, the paper provides examples of students' design proposals for the university campus demonstrating their capability to integrate active technical solutions and passive design strategies achieving net-zero GHG, energy, water, and waste targets.
\end{abstract}

\section{Introduction}

Architecture and technology students are entering professions demanding leadership and innovation. Professional meta-disciplinary teamwork emphasizes aggregation of disciplines' skills in a sequential and convergent collaborative process. Such meta-disciplinary approach to collaborative teamwork, unfortunately, is not often nurtured in our institution of higher education, including the architecture, engineering, and technology programs. The metadisciplinary approach emphasizes students understanding the world in a holistic way by integrating disciplinary knowledge into a more comprehensive view while willing to collaborate and learn across the barriers between disciplines [1]. This course prepares students to address contemporary environmental policies demanding pursuit of the most effective solutions. The professional context for students taking the course reflects emerging professional ethics and business models emphasizing sustainable and resilient community development. To meet these professional and environmental challenges, students need to be prepared to lead in the design and management of high-performance buildings and districts.

1.1 The need for an Inter-Disciplinary course on Sustainable Technology Innovation for Urban Design course

Architects are taking the lead in designing sustainable and resilient communities. They have been instrumental in international effort to bridge global targets of twenty third Conference of the Parties (COP23) of the United Nations (UN) in Berlin and its preceding meetings. Their 
contribution is not only demonstrated in the Paris Agreement, but also in the contemporary international networks of cities such as C40 [2] and R100 [3]. The C40 and R100 efforts funded by the Bloomberg and Rockefeller Foundations are harnessing local policy commitment to mitigate GHG and adapt to climate change. Inside cities, public and private sector partners are working together at retrofitting districts to become carbon neutral, while striving for net-zero energy, waste, and water goals.

In 2006, the Board of the American Institute of Architects (AIA) adopted the 2030 Commitment responding to Architecture 2030's challenge to make new buildings and major renovation projects carbon neutral by 2030 [4]. Since 2010, architectural and urban design firms that have signed on to the 2030 Commitment have been using a uniform set of metrics and reporting protocols. In 2015, participating firms' database added 2.6 billion square feet of projects to the inventory. The result is a growing database of case studies demonstrating the effectiveness of low-carbon design strategies.

2030 Districts [5] is a nonprofit founded by Edward Mazria (FAIA) to support a network of private sector-led high performance districts. As of November 2017, 2030 Districts network included 18 districts. Primarily located in North America, these cities are piloting strategies through private-sector led initiatives. Mazria's plan to reduce carbon emissions $80 \%$ by 2050 for New York City [6] demonstrates the city's ambition and leadership in reinvesting in low-carbon cities [7]. Mazria exemplifies the leadership role architects and their allied professionals are playing in developing district-scale low-carbon strategies for cities. In many respects, he is a role model for the future of the profession as leader of interdisciplinary teams planning, designing, and implementing high-performance districts. He demonstrates how the next generation of professionals can collaborate effectively to create and implement integrated solutions.

Interdisciplinary teamwork requires exploration of both passive and indigenous as well as technology enabled active strategies that are enhanced through design at the scale of regions, cities, and buildings. These passive and active design strategies are being accelerated, made feasible, and enhanced with technology advances. However, to make cities smarter requires high functioning inter-disciplinary teams that can identify, develop, and use a set of common terminologies and processes. This was the primary motivation for introducing an interdisciplinary course that attract both architectural and students from engineering and technology with a goal of better preparing them lead and manage the design process for a sustainable future.

\section{$\underline{1.2 \text { Motivation for creating and providing the interdisciplinary learning opportunities }}$}

Meta-disciplinary or interdisciplinary coursework is not often applied to engineering, technology and architecture curriculum, which can be restricted by the state and professional accreditation requirements. In developing this course, the instructors strived to create conditions that built on the commonalities and complementing specializations of the professions while meeting accreditation criteria.

Given that architecture, technology, and engineering programs tend to attract students with different learning styles and cognitive strengths the course endeavored to create a friendly environment for students to practice real collaborative inter-disciplinary teamwork, instead of 
just 'working' in groups together. Students demonstrated their potential to advance the science and technology frontier through effective inter-disciplinary collaboration (Exhibit 1).

Colleagues from College of Architecture and engineering technology program in the College of Technology developed learning objectives and a pedagogical approach before co-teaching the course in Fall 2017. As project-intensive inquiry-based learning course it provided a platform for students to innovate within a real world project by applying design strategy and technical solutions developed in their capstone projects and studios.

\section{Exhibit 1}

Interdisciplinary Collaboration: Students Presenting to Campus Sustainability Committee

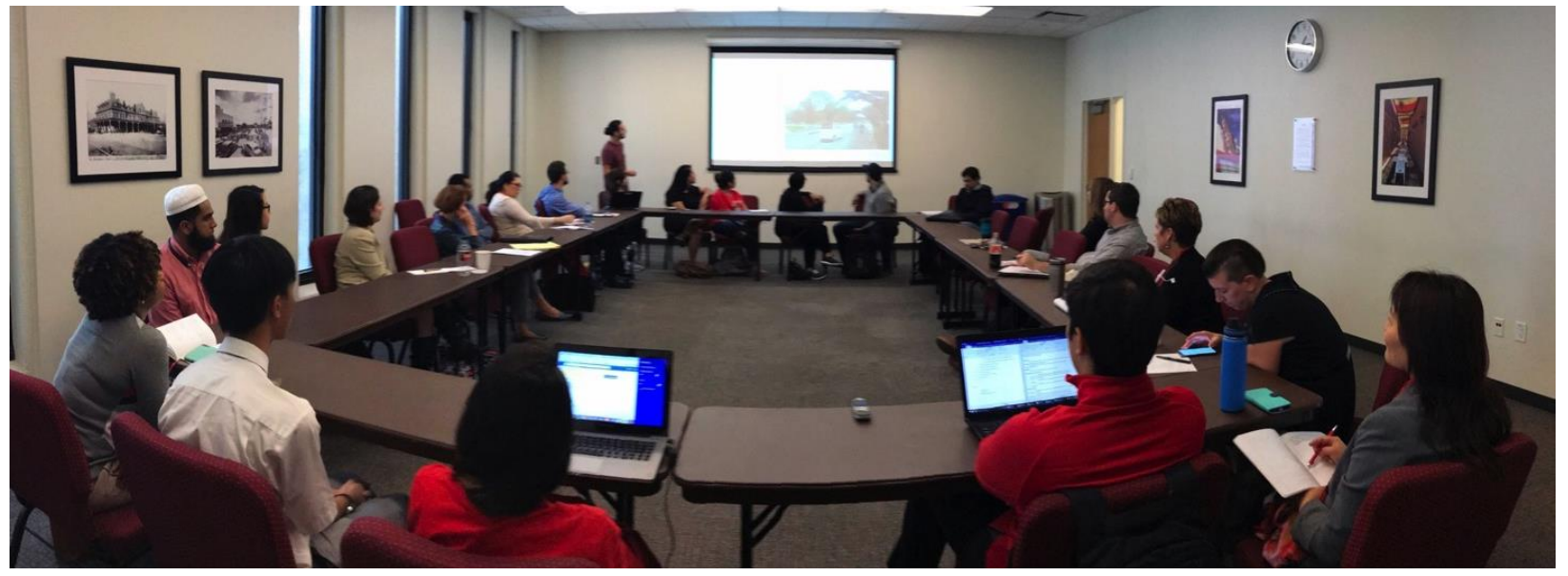

\subsection{Organization of the paper}

In the next section we provide an overview of the learning objectives from instructor perspective, expected student-centered learning outcomes, assignments and case studies, as well as the pedagogy used to deliver the learning material. Section 3 focuses on the students' research of sustainable urban design theory and models including details of the design of the assignments and corresponding learning objectives and outcomes, with students' product samples shown as exhibits. Section 4 presents results of students' final project proposal aiming to transform the university campus into a sustainable and resilient district. Section 5 presents the summary and the conclusion of the paper.

\section{Course Overview: Learning Objectives, Expected Learning Outcomes, and Pedagogy}

In the Fall of 2017, the faculty from the College of Architecture and Design and the College of Technology developed a project oriented interdisciplinary course on design of sustainable and high-performance districts. To fulfill the accreditation requirements of participating programs, the course was setup as a seminar course titled "Eco-Districts" in the College of Architecture and as a senior elective course titled "Sustainable Technology Innovation for Urban Design" in the College of Technology to emphasize the expected outcome of students from each program. The 
course is open to both undergraduate and graduate students enrolled in technology and architecture programs. The inter-disciplinary course is designed to facilitate students' progress towards their timely degree completion.

The course satisfies course requirements for undergraduate and graduate architecture students and expands the elective offerings at both undergraduate and graduate levels in the College of Technology. It is an undergraduate architecture research technology (Tech 7) course and a graduate seminar course (requiring a 3,000-word research paper) supporting graduate students seeking a sustainability concentration. The senior elective course offered in the College of Technology provided real world challenges technology and engineering students used in their course project or capstone senior project. The course highlighted the role technical innovation plays in addressing real-world challenges by revealing the relevance of technical details they need to master and their impact on society.

\section{$\underline{2.1 \text { Course Learning Objectives }}$}

The course focuses on the form of sustainable high-performance urban districts. Students studied how eco-districts are shaped by their response to climate, strategies they use to reduce greenhouse gas (GHG) emissions, to achieve high energy efficiency and production, better storm water management, and waste management. Special attention was paid to establishing ecological design objectives, baselines, targets, and strategies. Faculty identified a common set of sustainable and resilient urban design knowledge and skill sets, curriculum requirements from both program disciplines, as well as the potential career pathways for both undergraduate and graduate students taking the course.

Identified Overall learning objectives include:

1) To learn about urban ecological design theories and their applications.

2) To understand and experience the sustainable design and technology innovation practice as an interdisciplinary process.

3) To learn how to integrate eco-district strategies in urban design projects and develop technical solution for its staged design, development, implementation, and deployment.

\subsection{Expected Student-Centered Learning Outcomes}

Expected learning outcomes were based on a leaner-centered approach. At the end of the course, the students produced deliverables (assignments) corresponding to the student-centered learning outcomes listed below. These include a combination of outcomes related to architecture and engineering design, technology innovation, system integration, as well as professional ethics and communication skills.

After finishing the course, students are expected to be able to:

1) Demonstrate the knowledge of the ecological design theory and their applications.

2) Conduct individual research on high performance districts, urban design process, and players in order to realize sustainable and resilient (i.e., low carbon climate friendly) ecodistricts and present it as a 3,000-word case study paper. 
3) Conduct interdisciplinary team research on different ecological design theories and models, with both undergraduate and graduate students in programs of two colleges as team members and share the results (including ethics and legal aspects).

4) Demonstrate understanding and an ability to apply ecological design theory by establishing the baseline for the project site's GHG emission, energy use, water use, and waste management.

5) Demonstrate an ability to identify urban design objectives, targets and performance metrics, as well as strategies and technologies needed to create an integrated solution to achieve a net-zero eco-district design goal with respect to GHG emissions, energy, water, and waste management.

6) Integrate collaborative and investigative learning to build critical thinking skills.

7) Recognize the interplay between society and architectural and engineering design processes, including the importance of eco-district urban design, professional ethics, and concise and effective oral and written communication.

This course emphasized the relationship between technology and the urban design and built environment. Students had six deliverables for the course: two assignments, three projects, and one 3,000-word case study research paper. They worked as inter-disciplinary team members to research and present sustainability theories, conduct case studies of high-performance districts, and propose net-zero targets and strategies for the pre-defined university project site. By using the UH campus for their final class project, students were able to employ a design process that moved back and forth between theory and practice.

In a semester that was shortened by Hurricane Harvey, students worked within a compressed schedule to achieve the course's learning objectives and expected student centered learning outcomes. In addition, students shaped campus sustainability policies by presenting their research findings and eco-district design project. Both the University Master Planning team leaders and the University Sustainability Committee welcomed their net-zero project recommendations, asked questions about many details for each segment, and provided feedback on what students can do next to implement and deploy their recommendations on campus. Students' role in updating the campus GHG baseline and informing efforts to resolve serious storm-water challenges energized the dialog about what it means to become a sustainable campus.

\subsection{Expected Instructor Centered Learning Outcomes}

Faculty also established expected instructor centered learning outcomes in alignment of state and professional accreditation requirements as well as program curriculum while supporting development of interdisciplinary approach to teaching sustainability. Recent instructional delivery has been transformed in both architecture and engineering technology programs. Courses that emphasize project-based and service learning are also yielding community benefits. Courses that foster interdisciplinary collaborative teamwork among students are a natural extension to the mission and curriculum of both colleges. 
Instructor Centered Outcomes (ICOs) included the following:

1) Develop and test the interdisciplinary course on sustainable and resilient urban design curriculum by integrating high level architectural urban design theory and innovative technology solution development process.

2) Design and test project intensive and inquiry based learning activities for such an interdisciplinary course and identify best practices to guide and manage such course.

3) Develop faculty expertise in teaching sustainable and resilient urban design course that open to all students, STEM or non-STEM, interested in the topic.

4) Reflect and disseminate our results and experience with the research and education community.

\subsection{Course Pedagogy: Meta-disciplinary Approach to Project Based Learning}

Meta-disciplinary or interdisciplinary learning provides a platform for students to gain collaborative teamwork skills that are transferrable to their professional career. The course provided an encouraging environment for students to collaborate and develop common ecodistrict design vocabulary and protocols. Student teams researched and prepared formal case studies of exemplar eco-district design projects, and identified best practices used in the design process. They discovered why an interdisciplinary approach is a necessity for successful planning, implementation, and management of high-performance districts.

The interdisciplinary process of the course emphasizes creating a collaborative environment, sharing inquiry, scholarly objectives, and practical application [8]. The shift from multidisciplinary to interdisciplinary or meta-disciplinary instruction has been recognized as a method that allows design and STEM students to "uncover and acquire a cohesive set of concepts, competencies, and dispositions of science, technology, engineering, and mathematics (STEM) that they transfer and apply in both academic and real-world contexts" [9]. One of the benefits of the meta-disciplinary approach is that it enables students to develop a shared and common understanding of systems-level ecological frameworks and urban design models that are required when collaborating on eco-district design project. In a traditional multidisciplinary approach where people from multiple disciplines work in parallel, it can be difficult to overcome language barriers, inherent biases, and even coming up with a common problem statement [10] due to disagreements.

The course employed instruction delivery approaches found in professional programs' studio and lab courses where theory and technology intersect. In technology and engineering curriculum integration of theory and technology happens in laboratory courses and in the arts and design it is in studios. In addition, professional programs often use a project-based, learner-centered approach. The common element in these integrative courses is the introduction of a team-based project with a set of learning objectives and outcomes focusing on ethical professional and leadership skills.

\section{Ecological and Sustainability Design Theory}

Exploring sustainable design theory in interdisciplinary teams supports a process of "verbalizing a visual representation" of design project strategies [11]. Students applied their theoretical 
knowledge of ecological and sustainable design to the resilient campus design problem by reflecting on the theoretical underpinning prior to pursuing design solutions. The intermediate step of researching various sustainability theories allowed students to develop their own theoretical toolkit. The interdisciplinary teamwork also gave them the opportunity to benefit from different learning styles and instructional experiences [12]. Developing a common theoretical framework together also allowed them to better explore and articulate their technology-enhanced eco-design solutions. This approach places an emphasis on the diversity of perspectives of the group rather than individual learning.

In this section, we present the details of the course design with students' deliverables that demonstrate the pedagogy of shared reflection.

\section{$\underline{\text { 3.1 Sustainable and Resilient Urban Design Theory and Models }}$}

Students researched ecological theoretical frameworks and models for sustainable urban design promoted by researchers, nonprofit organizations, and communities as communications and policy tools (Exhibit 2). They collaborated to create a toolkit of ecological urban design and sustainability theories and models, gained deeper understanding how these were used to develop contemporary policies and plans, and applied them to convert 22.4-acres of North Campus of the University of Houston (UH) (mostly surface parking lot) into a sustainable and resilient ecodistrict.

\section{Exhibit 2}

Interdisciplinary Student Teams' Theoretical Toolkit
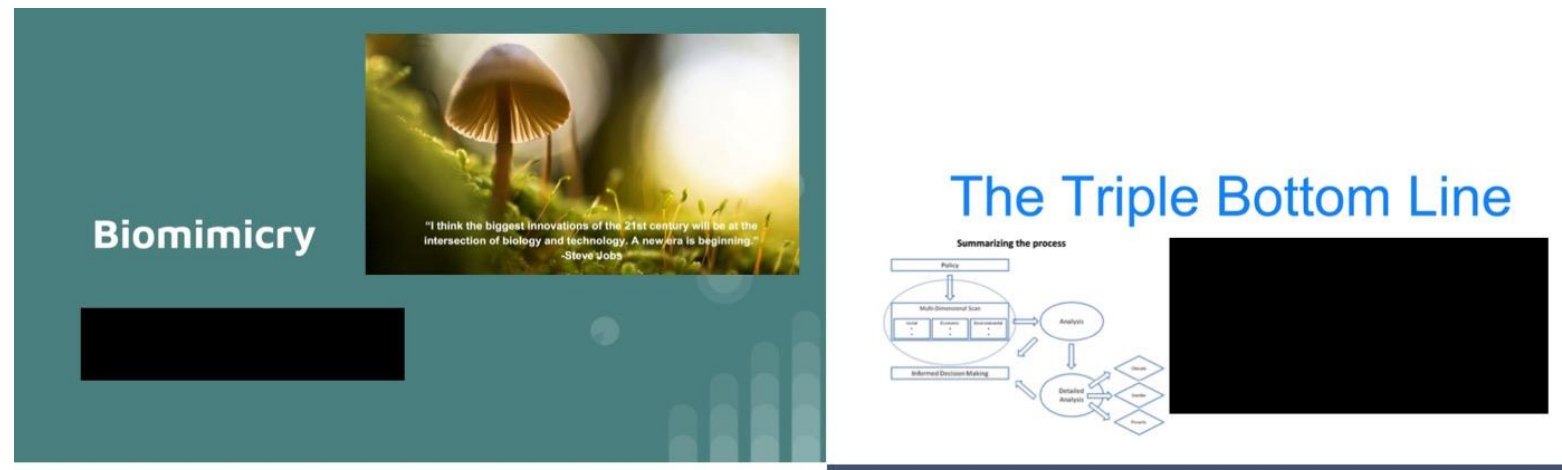

METABOLISM MODEL
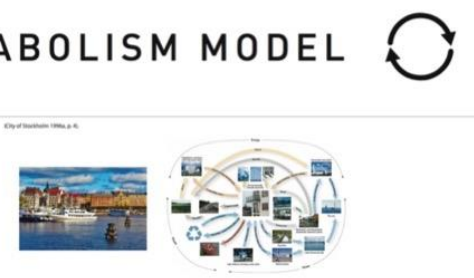

Natural Capitalism

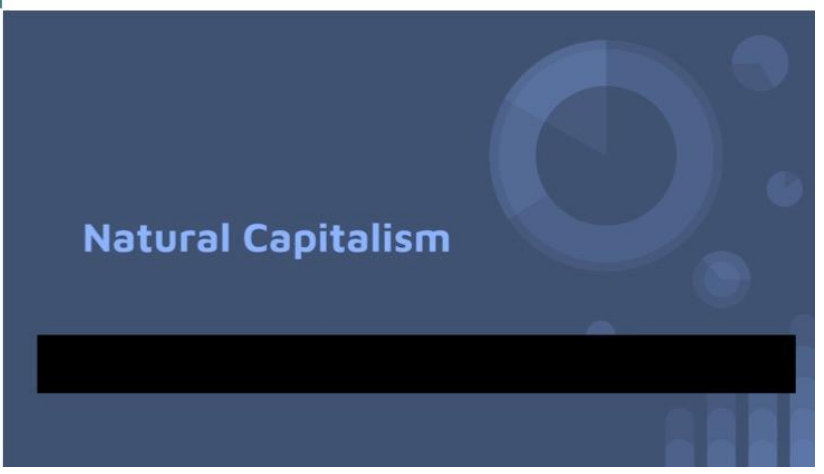


After getting introduced to high-level ecological urban design theories and case studies, students worked in teams and discussed how various policy, technology, and district management structures and infrastructures resulted from the eco-district design process. They examined the evolution of sustainability design theory influence on practice. Lectures and discussions supported student collaboration.

Samples of theory discussion topics included:

- Overview - universal experiences of cities and the design of the future smart city

- Patterns and order - effective strategies' influence on urban form

- Perspectives on sustainability theory

- One-earth model

- Bio-mimicry model

- Triple Bottom Line model

- Metabolism Model

Teams chose one particular theory model to research and learn. They presented their model to the class. Afterwards, the class reflected on how each theory model can be used to solve sustainability and resilience challenges facing UH's North Campus. The process enabled them to develop a common set of constructs and language for effective interdisciplinary collaboration. Students then applied their theoretical toolkit and model library on the final project to design a sustainable and resilient UH North Campus.

The process exposed students to instructional pedagogies quite different from what they usually experience in their corresponding "traditional" seminars allowing them to benefit from different learning experiences and design thought processes. The learner-centered approach to the course also benefited from the students' cultural diversity and their local and international life experiences.

\subsection{Exploring Best Practices and a Common Language for Sustainable and Resilient Design}

Students collaborated in preparing case studies of various types of eco-districts, planning processes, identifying stakeholders and partners, selecting best practices to use, and developing common language used in the eco-district protocols, policies and plans (Exhibit 3). This reinforced the connection between theoretical constructs and practice.

Discussion topics included:

- Contemporary ecological policies and plans

- Climate Action Plans

- Resiliency planning

- Long-life buildings and historic preservation

- 'Smart' Cities of tomorrow - the zero carbon, waste and energy challenge

Students' case study research and presentations reflected a wide range of urban design theories and sustainability planning models as well as their successful applications in different geographic and social-economic areas. They applied vocabulary and language used in the process of planning high performance districts and explained architectural designers' and engineers' roles 
in the planning and management process. Teams reviewed and compared various protocols, and identified targets and metrics they could use to measure eco-district performance. They studied a variety of eco-district project types with set protocols such as those identified and used in EcoDistrict Target Cities and 2030 Districts [5], and individual community climate action plans with their own targets and metrics.

\section{$\underline{\text { 3.3 Eco-District Case Study Research Papers }}$}

In addition to theoretical and technical knowledge, the course learning outcomes also emphasized professional written and verbal communication skills. Students applied their jointly developed understanding about ecological theories and sustainable urban design models and strategies in a formal case study research paper.

At minimum, the 3,000-word paper should include the following information:

- Overview of district assets and challenges (buildings, population, environment, climate, economy, etc.)

- Summary of goals, targets, metrics, strategies and outcomes

- Issues that motivated the preparation of the eco-district plan

- The organizations, key players, and deliverables in the process

- Key sustainable design features

- Conclusions that could be applied to the university course project

Exhibit 3

Eco-Districts Case Studies

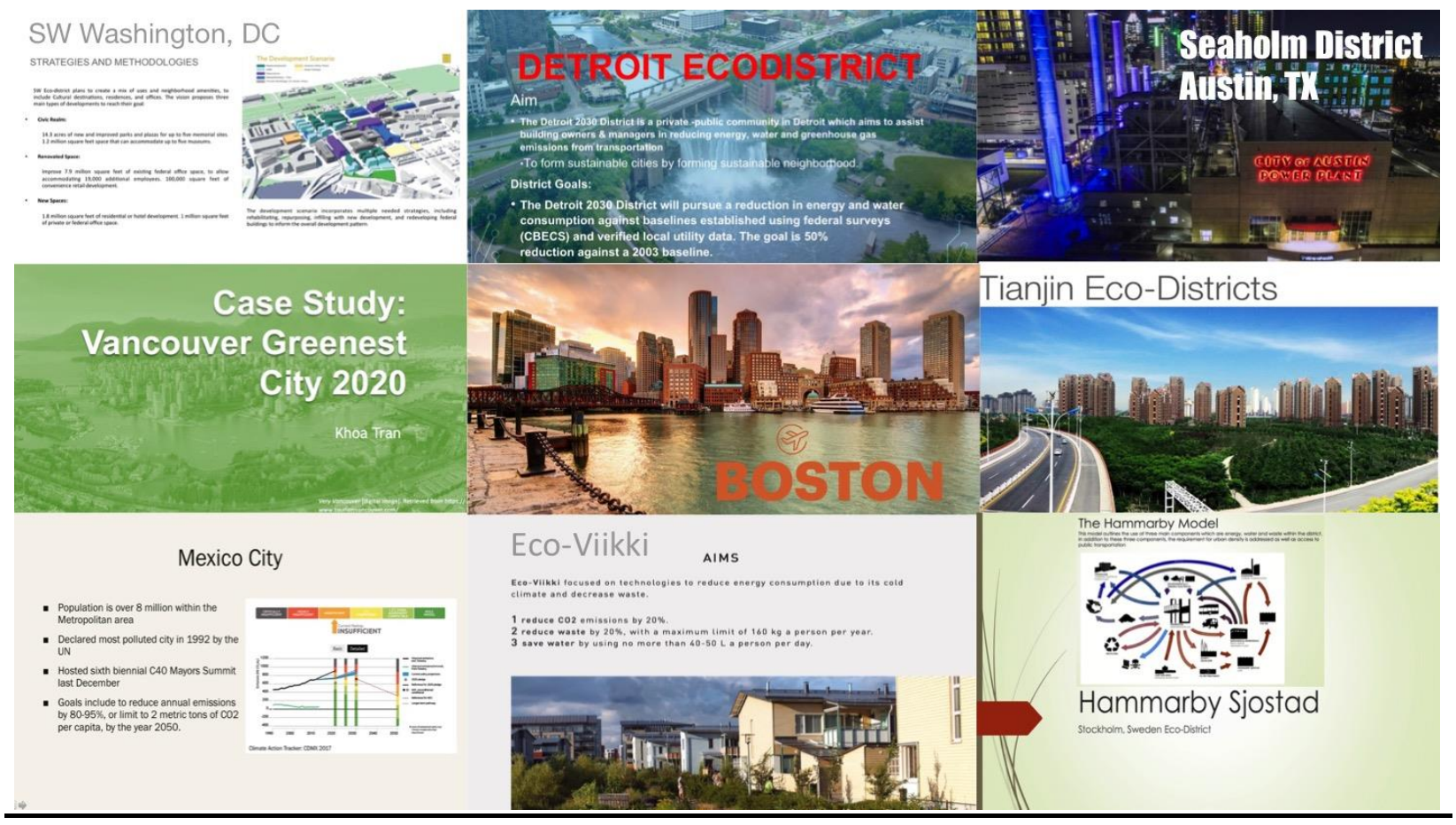


The eco-district case studies chosen by students for their research reflected the diversity of district types and locations, including sites in Europe, Asia, China, Mexico, and the USA. Some focused on districts with recently completed master plans while others explored implemented projects with performance data that could be used to track its progress towards meeting targets. To encourage their critical thinking and reflective learning, one third of the grade for the paper was based on the quality of reflection and conclusions from their case study, including their ideas on how the innovative practices used in the case study could be applied to the net-zero ecodistrict design process for the UH North Campus. All assessment rubrics for assignments like this are made known to students at the beginning of the course.

Students shared their case study research with the whole class, with discussion facilitated by instructors regarding their findings and reflections summarized in their 3,000-word paper. This experience helped them reach consensus regarding language and knowledge common to ecodistricts and design process as well as the performance metrics used. This enabled students to apply knowledge and tools learned in preparing environmental inventories, targets and goals, strategies, and implementation action plan for transforming UH North Campus into a sustainable net-zero eco-district.

\section{Final Project: Integrating Eco-District Thinking into Urban Design Projects and Technical Solution Development}

The course was designed and delivered using project-intensive inquiry-based interdisciplinary team learning approach. By assessing learner centered learning outcomes via their final project of the course, we were able to assess and evaluate both how much students learned at a high cognitive level $[13,14]$ and the success of the course, including its innovative delivery pedagogy and meta-disciplinary learning approach.

Students worked in four interdisciplinary teams to create sustainable and resilient eco-district plan for the UH North Campus. Each team proposed their own large-scale strategies and integrated technology solutions that, if implemented, could improve the environmental performance and the quality of life (i.e., learning experience) on campus.

The interdisciplinary student teams applied their newly acquired knowledge and skills to the 22.4-acre UH North Campus district. At present, the UH North Campus is primarily surface parking that causes flooding and lacks intermodal transportation connections. Students analyzed site including the campus ecological inputs and outputs, employed passive and active design and technology strategies to create a net-zero energy, water, and waste eco-district on campus. Students also updated greenhouse gas (GHG) emissions data for the whole campus previously prepared in 2013 using the Clean Air-Cool Planet Campus Carbon Calculator [15].

In all, these student teams delivered seven important findings and related recommendations for the campus leadership to consider.

Eco-District Analysis and Targets: Teams prepared an analysis of the site resulting in environmental baselines (with respect to energy, water, waste, and equivalent GHG emission) and net-zero targets. They researched campus water use, waste management, and energy consumption. Methods included university staff interviews, review of existing environmental 
reports, and mapping and measuring existing site conditions. They proposed demand reduction and supply-side goals to meet net-zero targets they identified for their eco-district design projects.

Identifying Key Performance Indicators for GHG Emissions: The UH campus GHG inventory indicated that $86 \%$ of emission came from purchased energy, commuting, and on-campus stationary sources. Teams focused on strategies that addressed key performance indicators including reduction in purchased energy and emissions from commuting to meet net-zero GHG emissions by addressing both the demand (consumption) and supply (source) for energy use and improving transportation choices on campus.

Net-Zero Energy: Students went beyond developing strategies for north campus and created plan to achieve net-zero energy target for the whole campus. They proposed a distributed and centralized renewable strategies for a campus-wide microgrid. Students calculated the amount of energy that could be generated from existing and future parking structures (9M Kwh) and building rooftops (34M kwh), and development of a bio-digester (4M kwh). Their calculation and analysis provided a 14.5-year payback period for the PV panel-based energy source and 15year payback period for the bio-digester. Students concluded, in combination with demand reduction strategies, these proposed supply-side solutions would result in a net zero energy campus.

Reduced Emissions from Commuting: The University is in the process of transitioning from a commuter school to a residential campus. However, reduction in emissions from commuting is still a challenge. Students proposed better intermodal connections at the perimeter of the campus, facilities for EVs, and a smart parking system. They demonstrated how a smart parking system and mobile App could be used to improve the performance of existing and new parking facilities by $15 \%$ resulting in $\$ 1.8 \mathrm{M}$ efficiencies per year in the new north campus parking structure with a pay-back period of less than 2 years. The students' presentation to the University Master Planning Leaders and University Sustainability Committee provided the final push for the university to invest in the new technology for existing parking facilities (including garages and surface parking) starting in Spring 2018.

Flood Resilience: Hurricane Harvey dropped nearly four feet of rain and flooded the underground facilities and several buildings' ground floors on UH campus. The north campus is about 90\% impervious due to its asphalt surface parking lots and its higher elevation directs stormwater towards the central campus. Students demonstrated how its development could offer an opportunity to mitigate flooding while improving the pedestrian experience on campus. They recommended development of "green fingers" concept (Exhibit 4) as an open space conveyance system for stormwater. The proposal included interconnected centralized, distributed, and on-site facilities that could detain a two-year (5") rain event and slowly filter stormwater into the watershed. Students used EPA software to calculate stormwater detainment.

Water and Waste: Students estimated demand reduction and supply-side strategies for reduction of domestic water consumption. They calculated clean water consumption reductions when investing in low-flow fixtures around campus and estimated the amount of greywater and rooftop rainwater that could be used for flushing toilets and irrigation. Students also identified strategies 
for reducing and managing waste including food and green waste available for energy production in digesters.

Campus Education and Advocacy: At the end of the semester, students presented their interdisciplinary research efforts to the University Master Planning managers and University Sustainability Committee. The University Master Planning managers were impressed with scope of students' proposals, particularly as they pertained to stormwater strategies because of the challenges they were facing after Harvey. They also provided invaluable feedback and encouraged students to expand on their flood resilience concepts and create more detailed proposal regarding campus stormwater detainment and open space system that can guide university resilience actions.

A more abbreviated presentation was made to the University Sustainability Committee and their sustainability consultant (Exhibit 1). The students focused on four overarching themes: proof of concept for net-zero energy; stormwater mitigation through implementation of the "green fingers" concept offering esthetic co-benefits; intermodal connections strategy for improved access to campus while reducing student commuting Vehicle Miles Traveled (VMT); and a smart parking system that would not only reduce VMT and emissions from cars searching for parking on campus but also would increase the campus parking revenues by $\$ 1.8 \mathrm{M}$ per year for the new 1,800 space north campus garage.

Exhibit 4

Stormwater Strategies: Green Fingers System

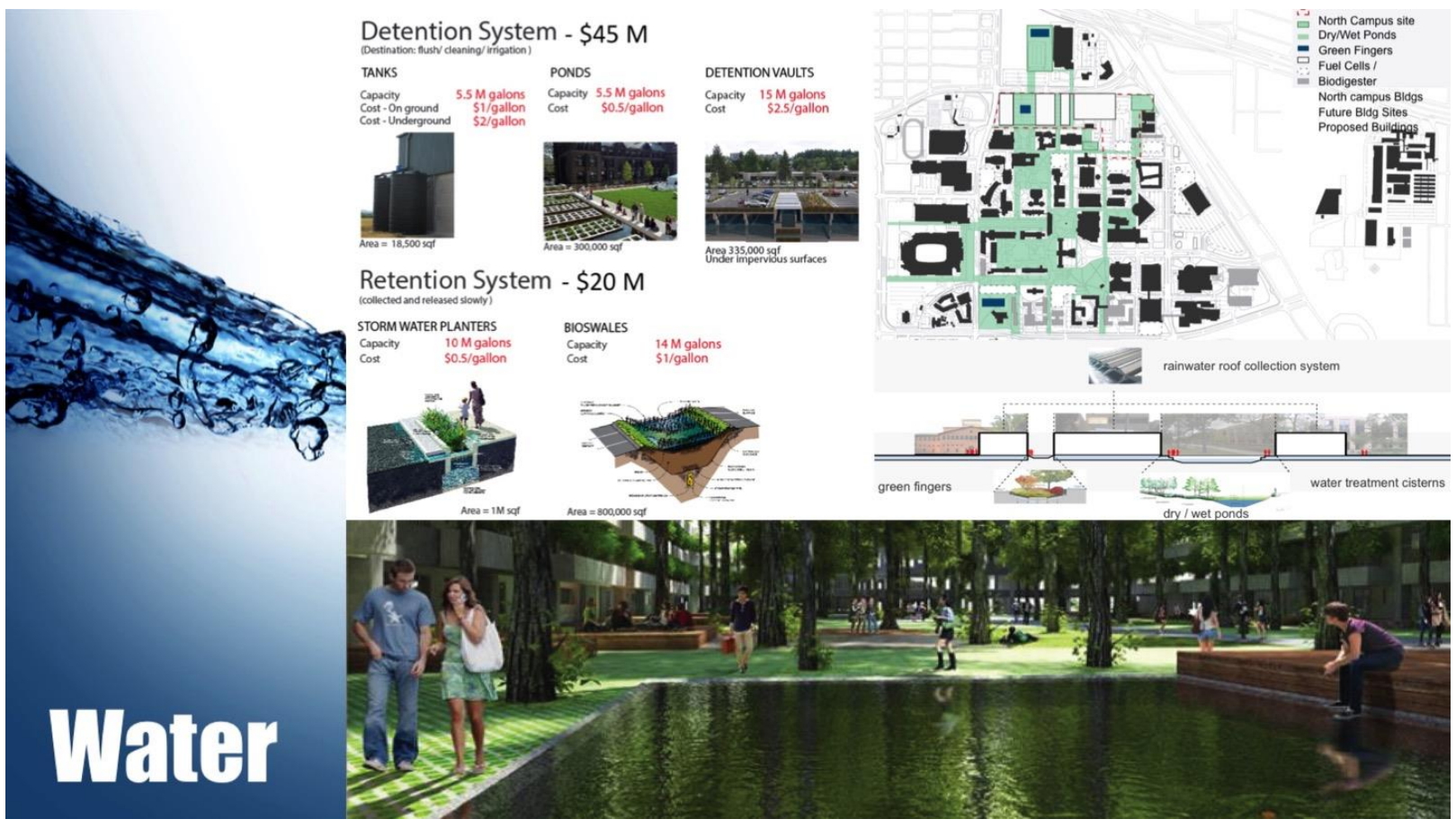




\section{Summary and Conclusions}

Meeting the learning objectives for the interdisciplinary eco-districts course utilized exploratory methods involving enquiry and discovery and formal case study method. These led to a complex final project employing a multifaceted approach throughout the eco-urban design process including site analysis, community involvement, target setting, and integration of sustainability strategies and models. Students were responsible for data collection, interacting with a variety of campus stakeholders, and pitching and discussing their proposals within an active campus planning and sustainability planning process. They learned, experienced, and made a policy impact (Exhibit 5).

Exhibit 5

Students Presenting Findings to Campus Master Planning Team

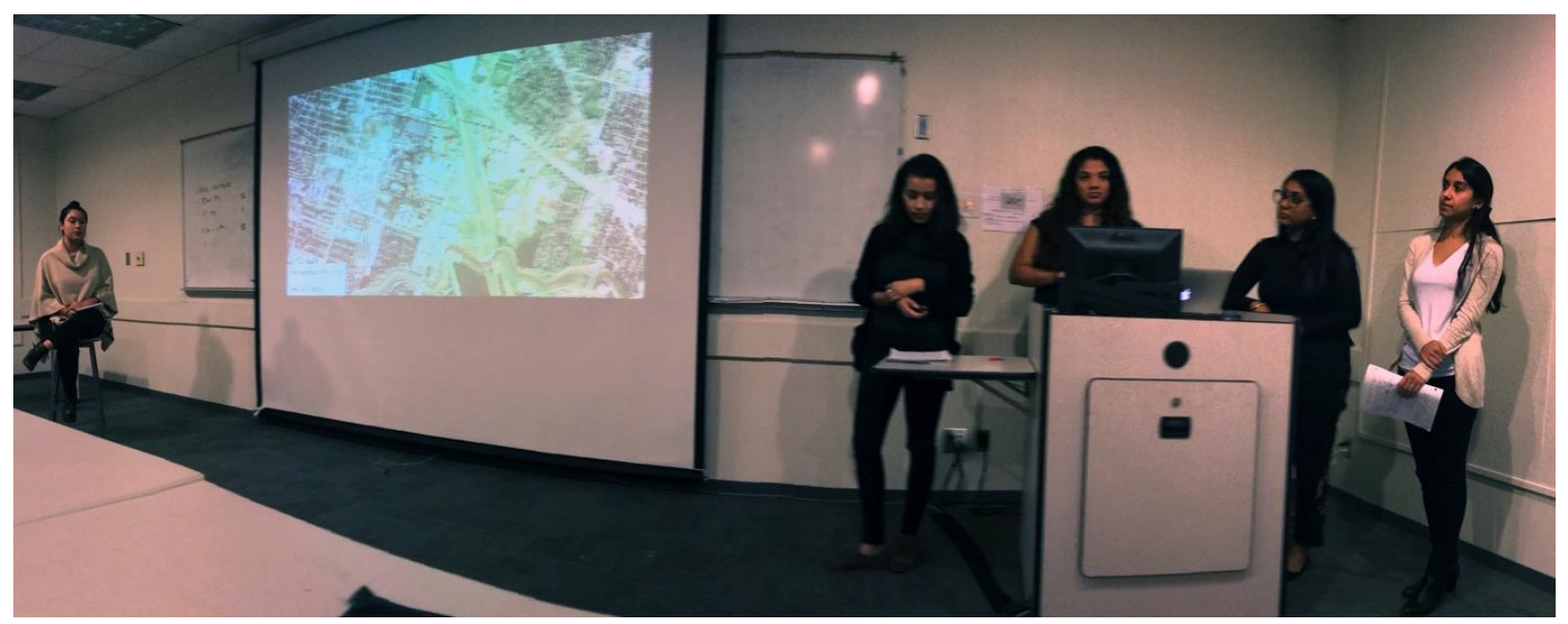

\section{$\underline{5.1 \text { Educational Outcomes }}$}

The semester focused on interdisciplinary teaching and learning where students learned how to apply innovative technologies to support the planning, design, and management of highperformance eco-districts. The semester included knowledge transferred by the professors. However, instructors focused on active learning activities, including student presentations and facilitated discussion and reflection. These activities were designed to distill eco-district design knowledge and skills and also improve students' collaborative interdisciplinary teamwork capabilities.

Students benefited from:

- Sharing and reflecting on common vocabulary and development of a shared theoretical toolkit they could use to form and communicate design strategies;

- An emphasis on the diversity of perspectives of the group rather than just individual learning; and

- Highlighting the horizontal relationship between technology and eco-design requiring students to move back and forth between theory and practice. 
Starting from scratch, students formed collaborative inter-disciplinary teams to meet course learning objectives and outcomes. They became team leaders, owning and managing the design process where they assembled the expertise to define expectation for high-performance ecodistricts. They designed and managed the team process and dynamic; and brought together required stakeholders and partners to take ownership and stewardship of the results.

\section{$\underline{5.2 \text { Successful Trial Run for Interdisciplinary Core Course for Sustainable Urban Systems }}$}

The eco-districts course ran as pilot for a new interdisciplinary Master of Science degree in Sustainable Urban Systems. The MS degree core courses include environmental analysis, ecological technologies workshops, and a practicum capstone. The multi-method and interdisciplinary nature of planning for high-performance cities and districts, mitigating ecological stressors, and implementing restorative environmental strategies have influenced the pedagogical approaches to teaching for the new degree.

\subsection{Lasting Impacts During a Challenging Semester}

The fall semester of 2017 at the University of Houston had massive flooding and recovery efforts as an impressionable backdrop and motivator for students and faculty. As future professionals, students experienced how to collaborate and innovate in a multidisciplinary team. Together, they imagined design and implementation strategies necessary to reduce climate impacts and adapt to a more uncertain environment.

The students' efforts have three lasting impacts on the campus planning process. First, the proposed smart parking plan and related details from students research has been forwarded to campus transportation and parking staff to inform their efforts to implement such a system. Secondly, the student efforts to update the five-year old campus GHG inventory has resulted in the campus investing in staff time and latest on-line Cool Planet calculator license that has built in benchmarking and strategy evaluation tools. Lastly, ongoing campus planning efforts are going to add a resilience component.

\section{References:}

1. Lantz, H. B. (2009). Science, Technology, Engineering, and Mathematics (STEM) Education What Form? What Function? pp. 1

2. C40 Cities. (2017). C40 Cities. Retrieved November 21, 2017, from C40 Cities: http://www.c40.org

3. 100 Resilient Cities. (2017). 100 Resilient Cities. Retrieved November 21, 2017, from 100 Resilient Cities: http://www.100resilientcities.org

4. American Institute of Architects. (2017). The 2030 Commitment-AIA. Retrieved November 2017, from AIA.org: https://www.aia.org/resources/6616-the-2030-commitment.

5. 2030 Districts. (2017). 2030 Districts. Retrieved November 20, 2017, from http://www.2030districts.org/

6. Architecture 2030. (2016, July 16). Achieving 80x50-Transforming New York City's Building Stock. Retrieved November 21, 2017, from Architecture 2030: http://architecture2030.org/achieving-80x50-transforming-new-york-citys-building-stock/ 
7. New York City. (2017). 80x50 Mayor's Office of Sustainability. Retrieved November 2017, from NYC Sustainability: https://www1.nyc.gov/site/sustainability/codes/80x50.page

8. Cardetti, F., \& Orgnero, M. C. (2013). Improving Teaching Practice Through Interdisciplinary Dialog. Studying Teacher Education, 9 (3).

9. Rider-Bertrand. (2007). What is STEM Education?

10. McKeller, J., \& Stien, D. (1976), Interdisciplinary Education for the Architect. Journal of Architectural Education, 34-35.

11. Ventura, J., \& Ventura, G. (2015). Exphrasis: Verbalizing Unexisting Objects in the World of Design. Design and Culture, 7 (2), 185-202.

12. Kolb, D. (2018, February 4). David Kolb. Retrieved 2018, from University of Leicester: https://www2.le.ac.uk/departments/gradschool/training/eresources/teaching/theories/kolb

13. Anderson, L.W. (Ed.), Krathwohl, D.R. (Ed.), Airasian, P.W., Cruikshank, K.A., Mayer, R.E., Pintrich, P.R., Raths, J., \& Wittrock, M.C. (2001). A taxonomy for learning, teaching, and assessing: A revision of Bloom's Taxonomy of Educational Objectives (Complete edition). New York: Longman.

14. Bloom, B.S. (Ed.), Engelhart, M.D., Furst, E.J., Hill, W.H., \& Krathwohl, D.R. (1956). Taxonomy of educational objectives: The classification of educational goals. Handbook 1: Cognitive domain. New York: David McKay.

15. Clean Air-Cool Planet Campus Carbon Calculator, https://sustainableunh.unh.edu/calculator 